\title{
Varicella zoster gastritis in an immunocompetent adult woman
}

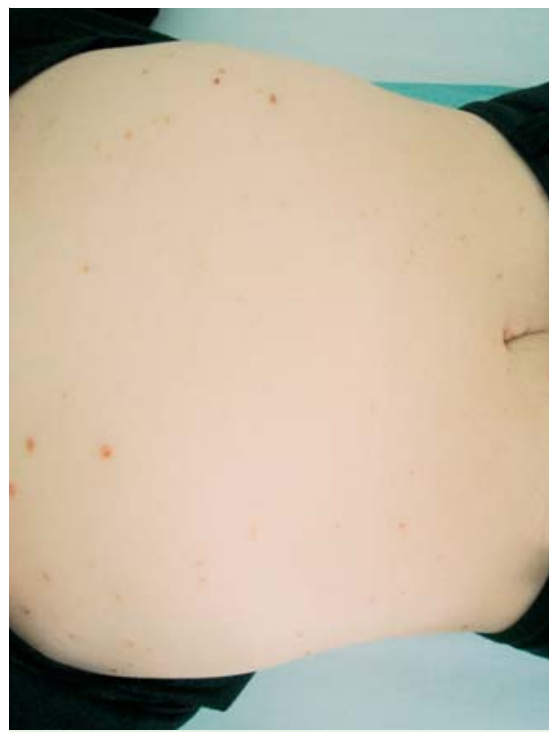

Fig. 1 Trunk appearance showing a generalized papular rash that had crusted over.

A 42-year-old Korean woman presented to the emergency room with severe epigastric pain and anorexia lasting for 7 days. She had developed a papulovesicular skin rash that began on the trunk and then spread to the face and limbs, accompanied by 3 days of fever and myalgia, 7 days prior to presentation. The woman had been diagnosed with chickenpox and treated with intravenous acyclovir (started on the first day of skin eruption) for 7 days at an outside clinic. Her medical history was not significant for immune abnormalities, disruption of mucosal integrity, or immunosuppressant medication, including non-steroidal anti-inflammatory drugs. Her vital signs were stable and an abdominal and chest examination normal except for the generalized papular rash that had crusted over ( Fig.1). Laboratory tests and a simple abdominal X-ray were normal. Upper gastrointestinal endoscopy revealed multiple round to oval discrete or confluent erosive lesions, approximately $0.3-0.8 \mathrm{~cm}$ in size, with slightly raised erythematous margins, involving the whole antrum, the lesser curvature side of the mid-body, and the fundus ( Fig.2). A rapid urease test for Helicobacter pylori was negative.
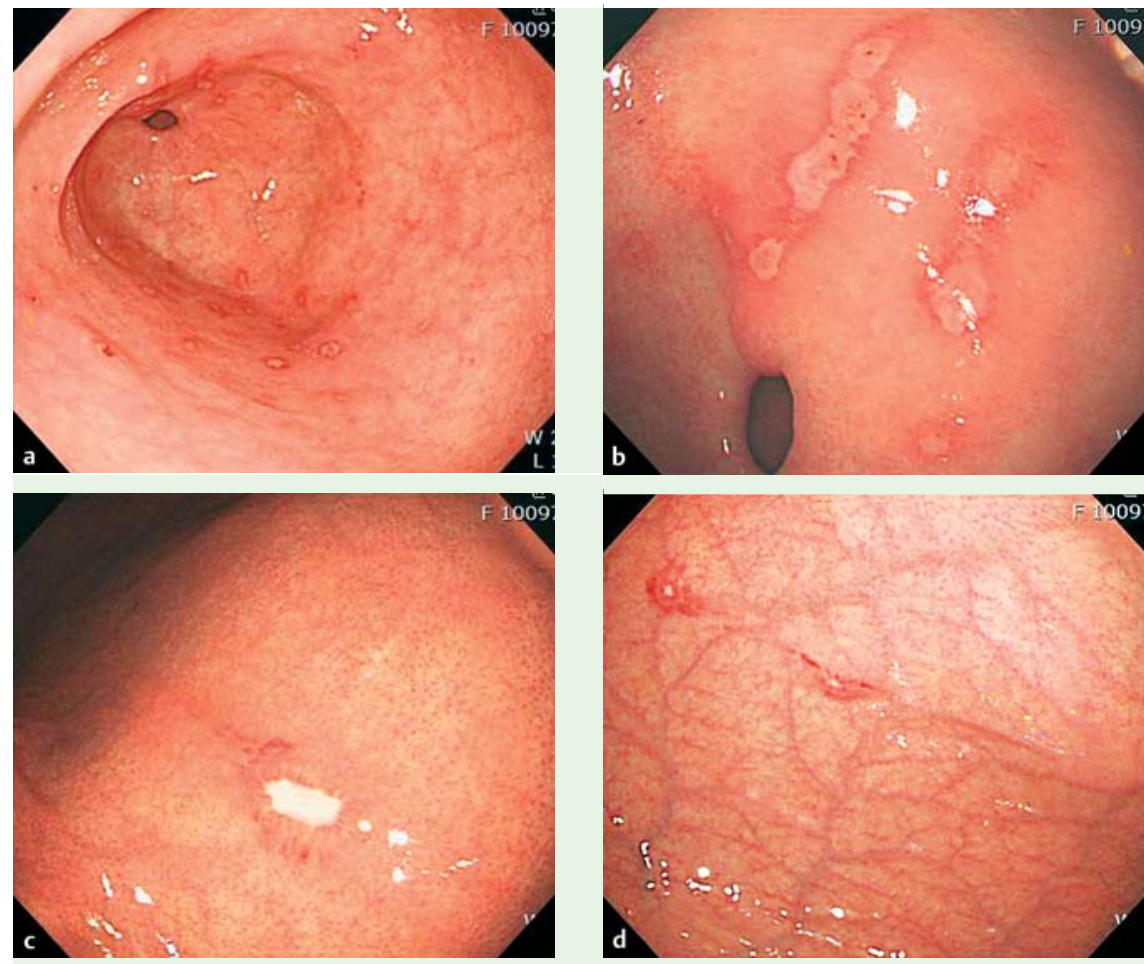

Fig. 2 Endoscopic findings showing: a multiple round to oval discrete erosive lesions, approximately $0.5 \mathrm{~cm}$ in size, with erythematous margins, involving the whole antrum; $\mathbf{b}$ multiple round to oval confluent erosive lesions, approximately $0.8 \mathrm{~cm}$ in size, with erythematous margins, on the lesser curvature side of the distal antrum;

The patient was treated only with an oral proton pump inhibitor, and the acyclovir was discontinued. Histopathological examination of the biopsy specimen was suggestive of non-specific acute gastritis without inclusion bodies ( Fig.3). However, polymerase chain reaction (PCR) for varicella zoster virus was positive, but culture was negative ( $\bullet$ Fig. 4 ). Follow-up endoscopy performed 1 week later showed marked improvement compared with the initially examined lesions, with symptom resolution. Follow-up endoscopy performed 2 months later showed normalization of the gastric mucosa.

Varicella zoster gastritis in immunocompromised patients is rare, and has never before been reported in an immunocom-

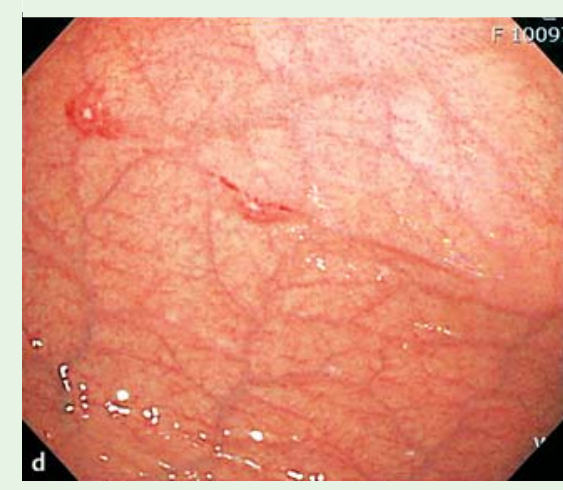

c an approximately $0.3 \times 0.8$-cm, ovoid, discrete erosive lesion with slightly raised erythematous margins, on the lesser curvature side of the midbody; $\mathbf{d}$ two approximately $0.3 \times 0.5-\mathrm{cm}$, ovoid, discrete erosive lesions with slightly raised erythematous margins, at the fundus.

petent adult. This is the first reported case of PCR-proven varicella zoster gastritis in an immunocompetent adult woman [1-3].

Endoscopy_UCTN_Code_CCL_1AB_2AD_3AF

Competing interests: None

\section{G. Kim, W. Moon, C. S. Lim}

Department of Internal Medicine, Kosin University College of Medicine, Busan, Korea 

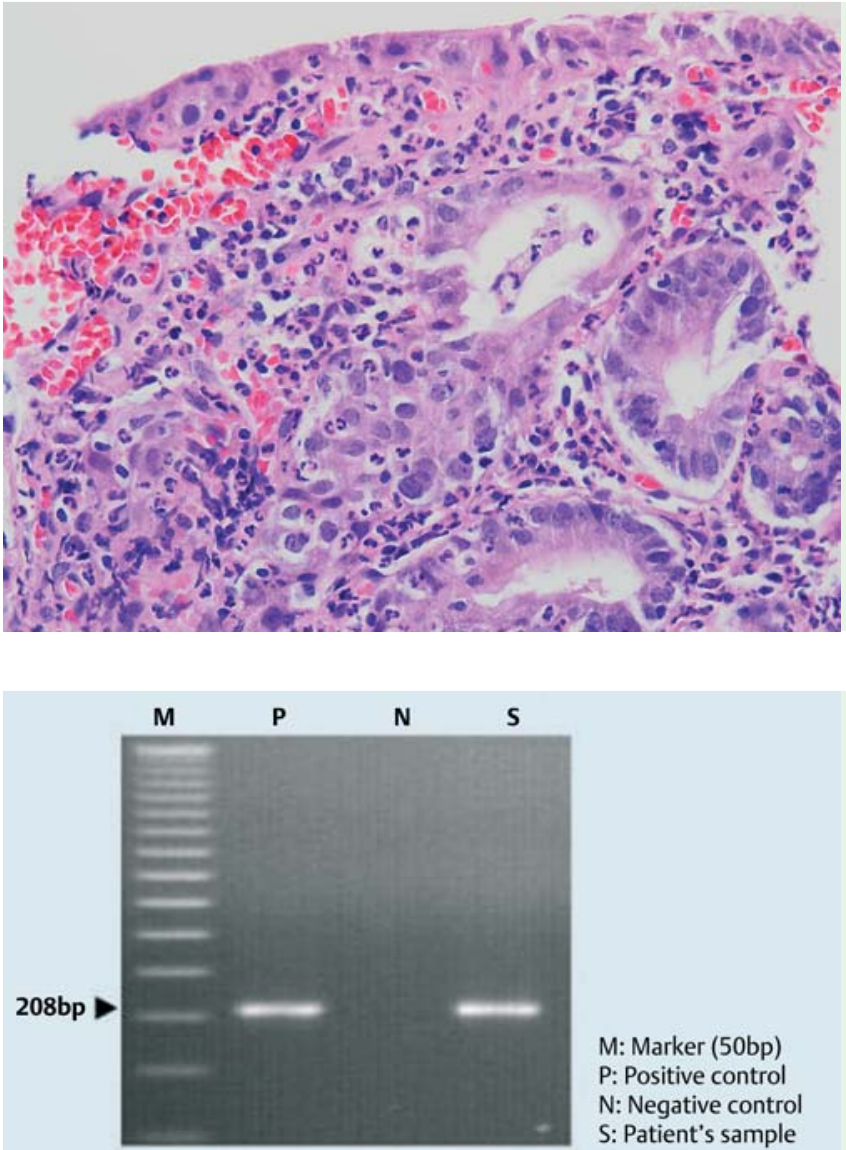

M: Marker (50bp)

P: Positive control

$\mathrm{N}$ : Negative control S: Patient's sample
Fig. 3 Histologica findings for the gastric erosive lesions, showing non-specific acute gastritis without inclusion bodies $(\times 400)$.

\section{References}

1 Rivera-Vaquerizo PA, Gómez-Garrido J, Vicente-Gutiérrez $M$ et al. Varicella zoster gastritis 3 years after bone marrow transplantation for treatment of acute leukemia. Gastrointest Endosc 2001; 53: 809-810

2 Scholl S, Hocke M, Hoffken K, Sayer HG. Acute abdomen by varicella zoster virus induced gastritis after autologous peripheral blood stem cell transplantation in a patient with non-Hodgkin's lymphoma. Acta Haematol 2006; 116: $58-61$

3 Baker CJ, Gilsdorf JR, South MA, Singleton EB. Gastritis as a complication of varicella. South Med J 1973; 66: 539-541

\section{Bibliography}

DOI http://dx.doi.org/

10.1055/s-0032-1310035

Endoscopy 2012; 44: E381-E382

(c) Georg Thieme Verlag KG

Stuttgart · New York

ISSN 0013-726X

chain reaction (PCR) of the endoscopic gastric biopsy specimen, showing positivity for varicella zoster virus.

Corresponding author

\section{W. Moon, MD}

Department of Internal Medicine Kosin University College of Medicine

34 Amnam-dong

Seo-gu

Busan 602-702

Korea

Fax: +82-51-9903005

moonone70@hanmail.net 